\title{
Effect of construction-related activities and vessel traffic on marine mammals
}

\author{
Ross M. Culloch ${ }^{1, *}$, Pia Anderwald ${ }^{2}$, Anja Brandecker ${ }^{1}$, Damien Haberlin ${ }^{1}$, \\ Barry McGovern ${ }^{1}$, Róisín Pinfield ${ }^{1}$, Fleur Visser ${ }^{3}{ }^{4}$, Mark Jessopp ${ }^{1}$, Michelle Cronin ${ }^{1}$ \\ ${ }^{1}$ MaREI Centre, Environmental Research Institute, University College Cork, Beaufort Building, Ringaskiddy, Co. Cork, Ireland \\ ${ }^{2}$ Swiss National Park, Chastè Planta-Wildenberg, 7530 Zernez, Switzerland \\ ${ }^{3}$ Kelp Marine Research, Loniusstraat 9, 1624 CJ, Hoorn, The Netherlands \\ ${ }^{4}$ Behavioural Biology Group, Leiden University, PO Box 9505, Leiden, 2300 RA, The Netherlands
}

\begin{abstract}
During the construction of a gas pipeline from an offshore gas field in northwest Ireland, a year-round shore-based marine mammal monitoring programme was undertaken. Using $6 \mathrm{yr}$ of data, generalised estimating equations-generalised additive models (GEE-GAMs) were used to investigate if construction-related activity and vessel traffic influenced the occurrence of common dolphin, minke whale, harbour porpoise and grey seal within the area where the pipeline made landfall. Construction-related activity reduced harbour porpoise and minke whale presence, whilst an increase in vessel numbers (independent of construction-related activity) reduced common dolphin presence. All species showed some degree of annual and seasonal variation in occurrence. For common dolphins and harbour porpoises, we found similar seasonal patterns to those reported in broader Irish waters, which tentatively suggests that seasonal patterns persisted irrespective of construction-related activity or vessel traffic, indicating that any impact might have been only short-term. Multiple construction-related activities occurred simultaneously in different areas, and the inter-annual variation may, in part, be an indication of variation in species' response to particular activities, their intensity and their location. However, the precise location of the activities was not regularly recorded, limiting our ability to investigate the fine-scale spatio-temporal impact of the diverse range of construction-related activities. Improved communication and coordination between developers, regulators and scientists will help ensure that monitoring programmes are effective and efficient, to better inform our understanding of potential impacts and to mitigate effectively against them for future developments.
\end{abstract}

KEY WORDS: Seismic survey · Sonar - Dredging · Cumulative impact - Anthropogenic noise · Marine mammal observer $\cdot$ Odontocete $\cdot$ Mysticete $\cdot$ Phocid

\section{INTRODUCTION}

Beyond natural stochastic processes, anthropogenic activities, such as the construction, operation and maintenance of marine developments can influence the abundance, distribution and behaviour of marine mammals (Teilmann \& Carstensen 2012, Pirotta et al. 2013, Thompson et al. 2013a). During the construction phase in particular, the site and its designated transit route tend to experience increased vessel traffic and anthropogenic noise. As most marine mammals rely heavily on sound to communicate, detect prey and/or navigate, the need to quantify the potential impact of construction-related activity has gained substantial momentum over the last 10 to $15 \mathrm{yr}$ (Nowacek et al. 2007, Hildebrand 2009). There is now a large body of research-based evidence showing that particular construction-related activities, such as pile driving (Brandt et al. 2011), seismic surveys (Stone \& Tasker 2006) and dredging (Pirotta et al. 2013) have negative 
impacts on marine mammals. Depending on the animals' proximity to the activity, the type of activity, and the context in which the area is being used by the animals, these may range from behavioural responses, such as displacement (Teilmann \& Carstensen 2012, Thompson et al. 2013a) through to physiological impacts, including a temporary or permanent threshold shift in hearing (Kastak et al. 2005, Lucke et al. 2009, Kastelein et al. 2014).

As marine mammals are highly mobile, designing feasible and appropriate monitoring programmes can be a challenge. This is further complicated by variation in spatial and temporal trends in occurrence attributable to stochasticity within the marine environment (e.g. Nottestad et al. 2015). In some cases, such as harbour maintenance and development, the activities undertaken can be discrete and cover relatively small geographical regions (Pirotta et al. 2013); however, for large-scale projects, it is possible for developments to have multiple vessels, often conducting different activities in close proximity to one another. This makes successfully pinpointing direct impacts of specific construction-related activities on marine mammals difficult (e.g. Richardson et al. 1990). In addition to these mounting challenges, monitoring projects are often constrained financially (Taylor et al. 2007), which makes the conventional approaches of double-platform boat-based or aerial line transects (Evans \& Hammond 2004) unfeasible. Consequently, suitable vantage points for shore-based watches are often employed as a cost-effective method for monitoring marine mammals in coastal areas. Although these platforms are geographically constrained, valuable data on trends in occurrence (Mendes et al. 2002, Anderwald et al. 2012, Embling et al. 2015), displacement patterns (Teilmann \& Carstensen 2012, Pirotta et al. 2013) and fine-scale habitat preferences (Mendes et al. 2002, Bailey \& Thompson 2010) can be obtained.

In 2002, construction work began at a gas field, $\sim 60 \mathrm{~km}$ offshore from northwest County Mayo, Ireland, a region recognised as an important cetacean habitat (Gordon et al. 1999, Anderwald et al. 2012, Wall 2013). As a condition of the developer's licence, in 2001, University College Cork (UCC) was subcontracted to conduct a marine mammal monitoring programme in close proximity to the designated landfall site of the gas pipeline. At that time, there were no recommendations in place for pre- or post-consent monitoring of marine mammals in Ireland. Consequently, the developers followed the existing regulatory requirements, opting for intermittent shore-based marine mammal monitoring that coincided with periods of construction-related activity. In 2009 the importance of year-round monitoring was stressed, which led to the developers allocating more resources to the programme to allow continual shore-based monitoring. The present study uses these data from 2009 onwards to investigate the impact of vessel traffic and construction-related activity on the occurrence of 4 species of marine mammal in close proximity to the landfall site of the gas pipeline.

\section{MATERIALS AND METHODS}

\section{Study area and data collection}

The gas pipeline makes landfall at Glengad, inner Broadhaven Bay (Fig. 1); the outermost part of the bay is $10 \mathrm{~km}$ wide and is relatively shallow, with depths less than $50 \mathrm{~m}$. Tidal fronts occur primarily around Erris Head, and there are a number of narrower shallow tidal inlets and estuaries which flow into the inner bay, close to the landfall site. Monitoring occurred from February 2009 to September 2014, irrespective of whether or not construction-related activity was occurring, and included a 1 yr post-

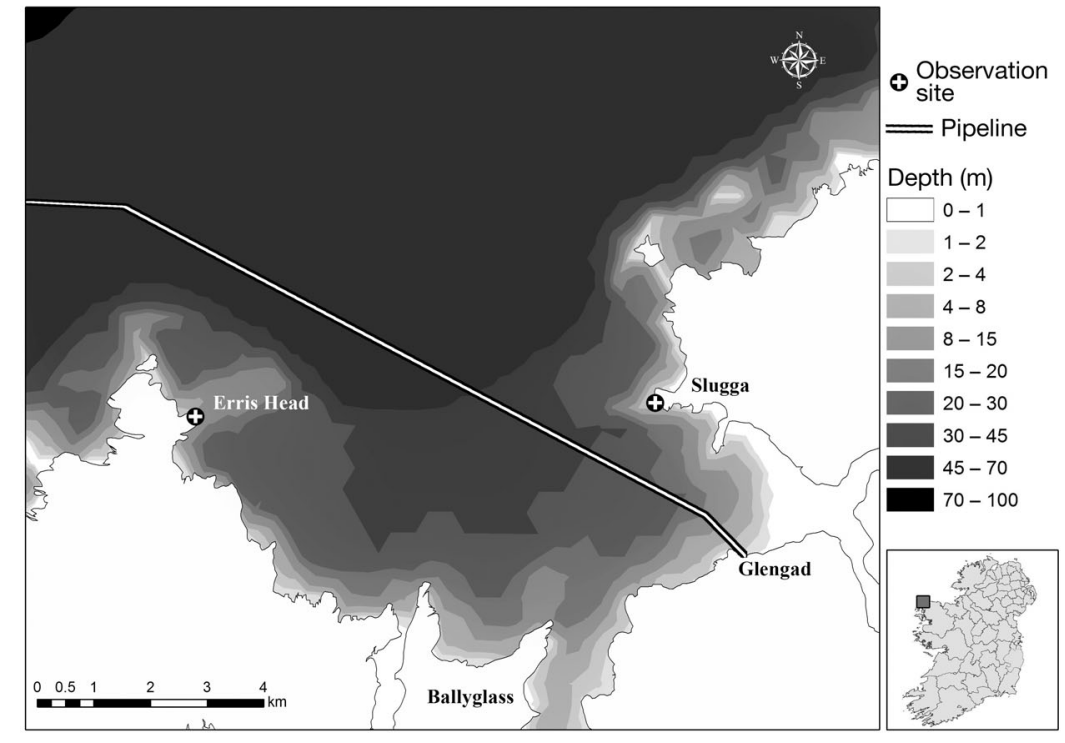

Fig. 1. Broadhaven Bay showing the location of the 2 shore-based vantage points and approximate location of the gas pipeline, which makes landfall near Glengad. Insert: location of the bay in relation to Ireland. Bathymetric contours were digitised from Admiralty chart 2703 'Broad Haven Bay and Approaches' 
construction monitoring period (September 2013September 2014). Construction and exploration activities, which included seismic surveys, multi-beam surveys, remotely operated vehicle (ROV) surveys, dredging, back filling, rock trenching, rock placement, rock breaking, pipe laying and umbilical laying, occurred in 2009, 2010, 2012 and 2013. In 2013 and 2014, maintenance activities, such as multibeam and ROV operations to assess the integrity of the pipeline, occurred. Not related to the pipeline, acoustic (multi-beam, single-beam, sub-bottom profiler) surveys for seabed mapping were conducted within Broadhaven Bay by the Geological Survey of Ireland (GSI) during $18 \mathrm{~d}$ in July 2014.

Information regarding construction-related activity was obtained a posteriori from independent marine mammal observer (MMO) reports. Under the code of practice between the developers and the regulators, MMOs were required to be present on vessels at the commencement of noise-generating activities. MMOs undertook watches for marine mammals prior to construction-related activity and had the authority to implement mitigation measures, e.g. a delay in operation, depending on the circumstances (e.g. water depth, activity type and proximity of the animal to the vessel). The days that MMOs were oneffort during noise-generating activities were included in the analysis as construction-related activity days. As the GSI seabed surveys required MMOs to be on board, these were also included in the analysis as construction-related activity.

Shore-based surveys for marine mammals were conducted from 2 elevated platforms on opposite sides of the bay at Erris Head ( $62 \mathrm{~m}$ above mean sea level [MSL]) and Slugga (54 m above MSL; Fig. 1). These vantage points were selected because they overlooked the landfall site of the pipeline and the harbour at Ballyglass, where many of the support vessels involved in construction-related activity were berthed. Scans of the bay were conducted for 60 min by 1 or 2 observers per site during daylight hours in favourable weather conditions (Beaufort sea state $<4$ and visibility $\geq 7 \mathrm{~km}$ ). During each scan the bay was systematically scanned using a telescope (Kowa) equipped with a $32 \times$ wide-angle eyepiece (covering areas $>2 \mathrm{~km}$ from the observation site) and handheld binoculars $(7 \times 50$; Steiner Navigator); the position of marine mammal sightings was taken using a theodolite (SOKKIA DT500A or FOIF DT205C). Vessel counts, vessel activity (e.g. fishing, construction-related, recreational) and environmental conditions were recorded during each scan. The positions of all vessels within the bay were recorded using the theodolite to provide a snapshot of vessel locations within the bay at ca. hourly intervals. Each scan was followed by a break of $\sim 60$ min to minimise observer fatigue. Time to the nearest high tide for each sighting was calculated using tidal data obtained from the Marine Institute (http://data.marine. ie) at the Ballyglass pier station situated within Broadhaven Bay.

\section{Data analysis}

The presence/absence of the 4 most regularly recorded species, common dolphin Delphinus delphis, minke whale Balaenoptera acutorostrata, harbour porpoise Phocoena phocoena and grey seal Halichoerus grypus was investigated at the scan-level, separately. To account for temporal autocorrelation in the model residuals, which was an issue for all 4 species, generalised estimating equations-generalised additive models (GEE-GAMs) were employed (Pirotta et al. 2011, Booth et al. 2013) using the $\mathrm{R}$ package, geepack (Højsgaard \& Halekoh 2006). The data were blocked by site and date, within which the residuals were not considered independent (Hardin \& Hilbe 2012). The explanatory variables included in the analysis were time to nearest high tide, the number of vessels within the bay (as a proxy for boat traffic) and Beaufort sea state, all of which were standardised to their mean (Zuur et al. 2009). Year, site and presence/absence of construction-related activity, defined as days that MMOs were on-effort during noise-generating activities (which included seismic surveys, multi-beam surveys, ROV surveys, dredging, back filling, rock trenching, rock placement, rock breaking, pipe laying and umbilical laying) were included as factors, and day-of-year was included as a B-spline with $3 \mathrm{df}$, which was applied using the $\mathrm{R}$ package splines ( $\mathrm{R}$ Core Team 2015). Cyclic splines are not available in this package; as such, the priority was to account for the temporal autocorrelation in the residuals.

The site, the time to nearest high tide, vessel counts (boat traffic), day-of-year (seasonality) and year were included in the models because they have all been shown to affect the behaviour, temporal presence and/or distribution of marine mammals (Mendes et al. 2002, Booth et al. 2013, Pirotta et al. 2015), whilst Beaufort sea state is widely acknowledged to influence detectability of marine mammals (Evans \& Hammond 2004). The explanatory variable year was used to assess, on a broad temporal scale, whether or not the intensity of construction-related activity, 
defined as the number of days of the year on which construction-related activity took place, had any influence on the occurrence of marine mammals within the bay. In turn, to investigate the influence of construction-related activity at a fine temporal scale, the presence/absence of construction-related activity on days when shore-based surveys were undertaken was included in the models. In the MMO reports, GPS coordinates of the active vessel were recorded irregularly; therefore, identifying the location of noise-generating vessels throughout their activities was not always possible. Instead, the location and density of vessels that were identified from shorebased surveys as assisting (e.g. support vessels transporting staff and materials) and/or being actively involved in construction-related activities were plotted by year to give an indication of where construction-related activity was likely to be occurring within the bay on days on which scans were undertaken. Vessel density was calculated using the kernel density tool in ESRI ArcGIS (version 10.2) using an output cell size of 100 and a search radius of 1000 .

The number of vessels in the bay was significantly higher on days of construction-related activity $(t=18$, $\mathrm{df}=603, \mathrm{p}<0.0001)$. Consequently, 2 model structures for each species were used, one excluding construction-related activity and one excluding the vessels counts. To allow for direct comparison between the model structures, the same dataset was used. The generalised variance inflation factor (GVIF) was used to assess multicollinearity between the explanatory variables. The independence and an autoregressive (AR1) correlation structure were compared for each species for both global models (the models containing all explanatory variables) (Hardin \& Hilbe 2012) using the quasi-likelihood information criterion (QIC; Pan 2001) where the model with the lowest QIC is considered to have the more appropriate correlation structure.

\section{Model selection and goodness-of-fit}

To avoid step-wise regression (Whittingham et al. 2006, Hegyi \& Zsolt Garamszegi 2011), all possible combinations of the global model were compared to one another. To compare models within the same correlation structure the QICu was used (Hardin \& Hilbe 2012). Model inference was made using the best model and the models within a threshold of $\triangle \mathrm{QICu}=$ 6 of the best model (i.e. a confidence set; cf. Burnham et al. 2011, Richards et al. 2011). This approach acknowledges that the model with the lowest QICu score is not necessarily the most parsimonious model. Furthermore, to avoid retaining overly complex models, a model was only retained if its $\triangle \mathrm{QICu}$ was smaller than the $\triangle \mathrm{QICu}$ of all its simpler nested models (Burnham \& Anderson 2002, Richards 2008, Richards et al. 2011). The level of support for the influence of an explanatory variable was assessed based on the percentage of models within the confidence set that retained the explanatory variable of interest. As the model structures are competing hypotheses, this model selection process was only undertaken for the model structure with the overall best model (lowest QICu) for each of the 4 species.

The goodness-of-fit of the best model was evaluated using a confusion matrix, in which the binary predictions from the model were compared to the observed presence/absence of the species of interest. These were expressed as the proportion of occurrences correctly classified by the fitted model (Fielding \& Bell 1997). The cut-off above which a predicted probability was classified as a presence was selected using a receiver operating characteristic (ROC) curve, which plots the sensitivity (true-positive rate) versus the specificity (false-positive rate) for a binary response whilst the cut-off probability is varied (Zweig \& Campbell 1993). Following Pirotta et al. (2011), the best cut-off probability for the observed data was calculated as the point where the distance between the ROC curve and the $45^{\circ}$ diagonal was maximised. The area under the ROC curve (AUC) was calculated as an additional measure of model performance, where the closer to 1, the better the model (Boyce et al. 2002). The confusion matrix and the ROC curve were calculated using the R packages ROCR (Sing et al. 2005) and PresenceAbsence (Freeman \& Moisen 2008).

\section{RESULTS}

Shore-based surveys from at least 1 of the 2 vantage points were conducted on $327 \mathrm{~d}$ over the $6 \mathrm{yr}$, comprising 1551 scans of the bay. Sightings of common dolphin, minke whale, harbour porpoise and grey seal occurred in 160, 110, 76 and 179 scans, respectively. Of the $380 \mathrm{~d}$ on which construction-related activity was undertaken, 95 had at least 1 scan on that date. Within the bay, vessels that were identified from shore-based observations as assisting (e.g. support vessels transporting staff and materials) and/or being actively involved in construction-related activities were typically recorded over the gas pipeline, with the highest density occurring close to the landfall site 

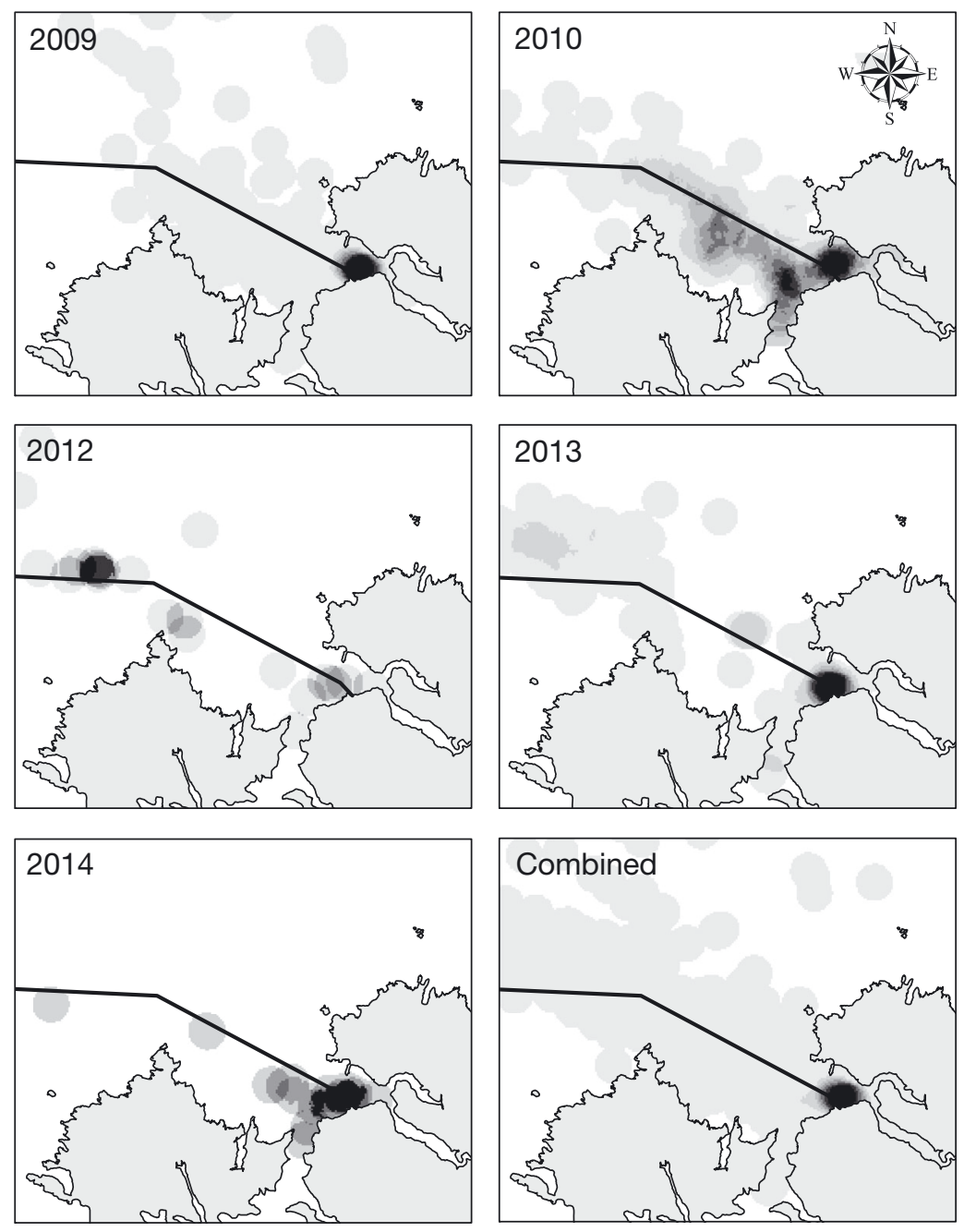

$012468 \mathrm{~km}$

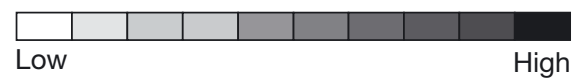

Fig. 2. Broadhaven Bay. Density maps of vessels that were identified from shore-based surveys as assisting (e.g. support vessels transporting staff and materials) and/or being actively involved in construction-related activities. 'Combined' plot is all data from 2009, 2010, 2012-2014. Black line represents the approximate path of the gas pipeline. There was no construction-related activity in 2011. Density scales are not uniform across maps; see Fig. S1 in the Supplement at www.int-res.com/articles/suppl/m549p231_supp.pdf for maps on a uniform scale

(Fig. 2). The greatest number of vessels within the bay occurred in 2009 (Fig. 3b), and across the 6 yr, there was a peak in vessel numbers during the summer months, which corresponded to the more intensive periods of construction-related activity (Fig. 3a).

Whilst controlling for factors that influence detectability and occurrence (e.g. tidal state, Beaufort sea state, site), there was evidence to suggest that construction-related activity or vessel traffic negatively influenced the occurrence of 3 of the 4 species (Table 1). For minke whales, harbour porpoises and grey seals the best model structure was construction-related activity, the converse was the case for common dolphins. The GVIF was $<2$ for the global model for the respective best model structure for all 4 species, indicating that multicollinearity was not an issue (Fox \& Monette 1992). The AR1 correlation structure was preferred for the global model for the respective best model structure for all 4 species (common dolphin $\triangle$ QIC $=$ 8.85 ; minke whale $\Delta$ QIC $=5.38$; harbour porpoise $\triangle \mathrm{QIC}=1.49$; grey seal $\Delta \mathrm{QIC}=5.27$ ). The goodness-of-fit metrics for the best model indicated a good model performance for all 4 species (AUC: 0.71-0.85, \% presence: 65-72, \% absence: 67-84; Table 1).

Day-of-year was retained in the best model for all 4 species, with strong support for the 3 cetacean species and moderate support for the grey seal (Table 1). Both common dolphin and grey seal occurrence was greater during winter, minke whale occurrence peaked in autumn and early winter and harbour porpoise occurrence peaked during spring and winter (Fig. 4). As such, a peak in common dolphin, harbour porpoise and grey seal occurrence often overlapped with times of the year when constructionrelated activity and vessel numbers were reduced (Fig. 3a). Year was retained in the best model for all 4 species (Table 1), with strong support for harbour porpoise and grey seal and modest support for common dolphin and minke whale; for all 4 species, 2009 had lower occurrence rates (Fig. 5). With respect to the number of days of construction-related activity, 2009 was the most intensive year, with all observed constructionrelated activity occurring solely within the inner bay at the landfall site; conversely, 2011 was the only year where no construction-related activity was undertaken (Figs. $2 \& 3 b$ ). Although the occurrence of all 4 species was lower in 2009, lower occurrences of these species did not always coincide with higher intensities of construction-related activity, and vice-versa (Fig. 5). The temporally fine-scale analysis found that both minke whales and harbour porpoises were less likely 

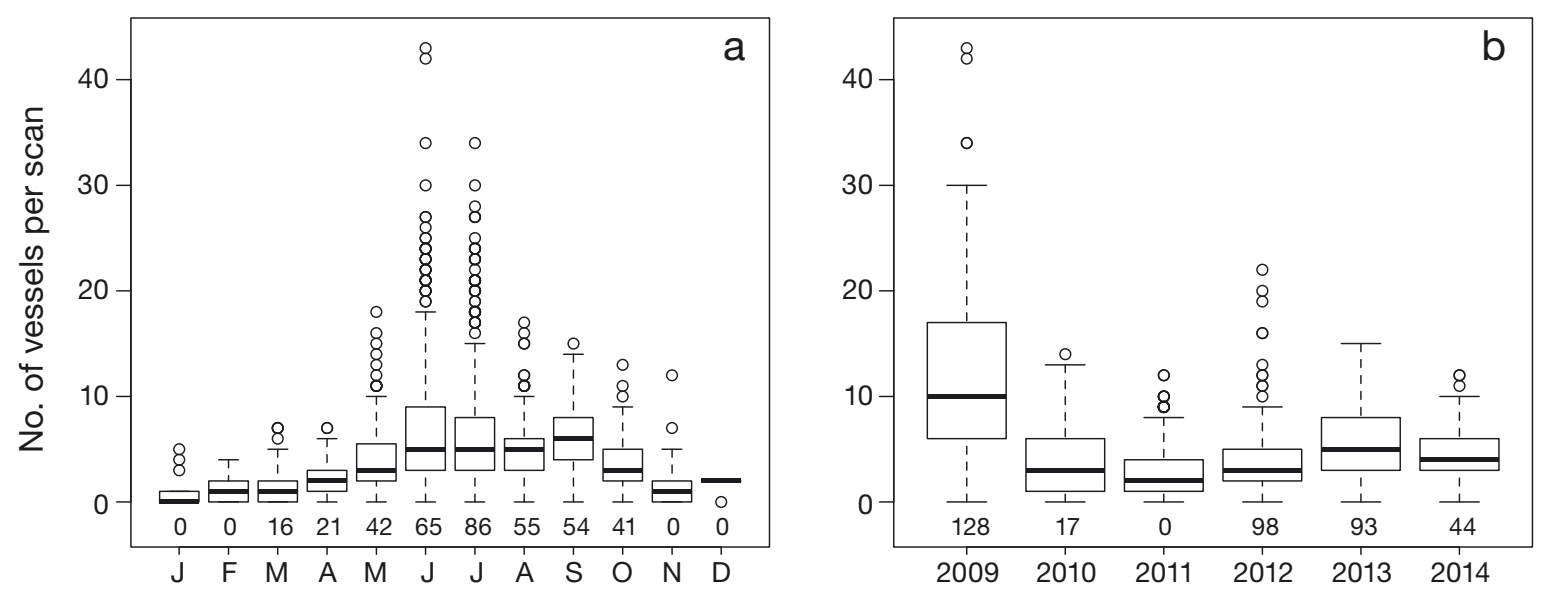

Fig. 3. Number of vessels counted in the bay during a scan for (a) each month and (b) each year. Total number of constructionrelated activity days is given on the $x$-axis for the respective months and years. Boxplots show the lower quartile, the median, the upper quartile and the whiskers, which extend to the most extreme data point that is no more than 1.5 times the interquartile range from the box; open circles indicate data points out with that range

Table 1. Confidence sets for the generalised estimating equations-generalised additive models (GEE-GAMs) for each of the 4 species. -/+: Direction of the relationship for continuous explanatory variables; site with the greater occurrence rate is indicated $(\mathrm{E}=$ Erris Head, $\mathrm{S}=$ Slugga). Percentage of models retaining the explanatory variable of interest is rounded to the nearest whole number. Number of models retained from a possible 63 is provided. Only the best model structure (construction-related activity or vessel counts) is presented, as indicated by the numerical value in the respective row. Goodness-of-fit metrics are provided for the overall best model. The equivalent table for the alternative model structures for each of the 4 species is presented in Table S1 in the Supplement at www.int-res. com/articles/suppl/m549p231_supp.pdf. AUC: area under the receiver operating characteristic curve

\begin{tabular}{|c|c|c|c|c|}
\hline & $\begin{array}{c}\text { Common } \\
\text { dolphin }\end{array}$ & $\begin{array}{l}\text { Minke } \\
\text { whale }\end{array}$ & $\begin{array}{l}\text { Harbour } \\
\text { porpoise }\end{array}$ & $\begin{array}{l}\text { Grey } \\
\text { seal }\end{array}$ \\
\hline \multicolumn{5}{|l|}{ Variables } \\
\hline Sea state & $67^{\mathrm{a}}(-)$ & $100^{\mathrm{a}}(-)$ & $100^{\mathrm{a}}(-)$ & $100^{\mathrm{a}}(-)$ \\
\hline High tide & $67^{\mathrm{a}}(-)$ & 0 & 0 & 0 \\
\hline Day-of-year & $100^{\mathrm{a}}$ & $100^{\mathrm{a}}$ & $100^{\mathrm{a}}$ & $50^{\mathrm{a}}$ \\
\hline Site & $100^{\mathrm{a}}(\mathrm{E})$ & $50^{\mathrm{a}}(\mathrm{E})$ & $50^{\mathrm{a}}(\mathrm{S})$ & $50^{\mathrm{a}}(\mathrm{E})$ \\
\hline Year & $50^{\mathrm{a}}$ & $67^{\mathrm{a}}$ & $100^{\mathrm{a}}$ & $100^{\mathrm{a}}$ \\
\hline Vessels & $100^{\mathrm{a}}(-)$ & na & na & na \\
\hline Construction-related activity & y na & $67^{\mathrm{a}}(-)$ & $50^{\mathrm{a}}(-)$ & 0 \\
\hline \multicolumn{5}{|l|}{ Model selection } \\
\hline No. of models retained & 6 & 6 & 4 & 4 \\
\hline \multicolumn{5}{|l|}{ Goodness-of-fit } \\
\hline Presence/absence (\%) & $68 / 67$ & $70 / 70$ & $72 / 84$ & $65 / 70$ \\
\hline AUC & 0.73 & 0.75 & 0.85 & 0.71 \\
\hline
\end{tabular}

to be sighted during scans on days in which construction-related activity was undertaken (Table 1, Fig. 6). This explanatory variable was retained in the best model for both species, although there was only moderate support for this effect (Table 1). For common dolphins, an increase in the number of vessels within the bay resulted in a decrease in the likelihood of sighting this species; there was strong support for this effect, and it was retained within the best model (Table 1, Fig. 6). Although the model structure containing constructionrelated activity was the best for grey seals, there was no support for the influence of this covariate (Table 1).

\section{DISCUSSION}

This study provides evidence that, on a fine-temporal scale, the occurrence of common dolphins, minke whales and harbour porpoises within the bay was reduced by construction-related activity or vessel traffic. Inter-annual variation was also an influential factor in the occurrence of all 4 species; this was especially true for harbour porpoises and grey seals. For all 4 species, occurrence was low in 2009 as compared to subsequent years, which corresponded to the most intensive year of constructionrelated activity. Of those factors that it was not possible to include in the analysis, prey availability is one that inevitably influences distribution and abundance of marine mammals (e.g. Nottestad et al. 2015), and although there is a paucity of research on the direct and indirect impact of construction-related activity on fish species, there is 

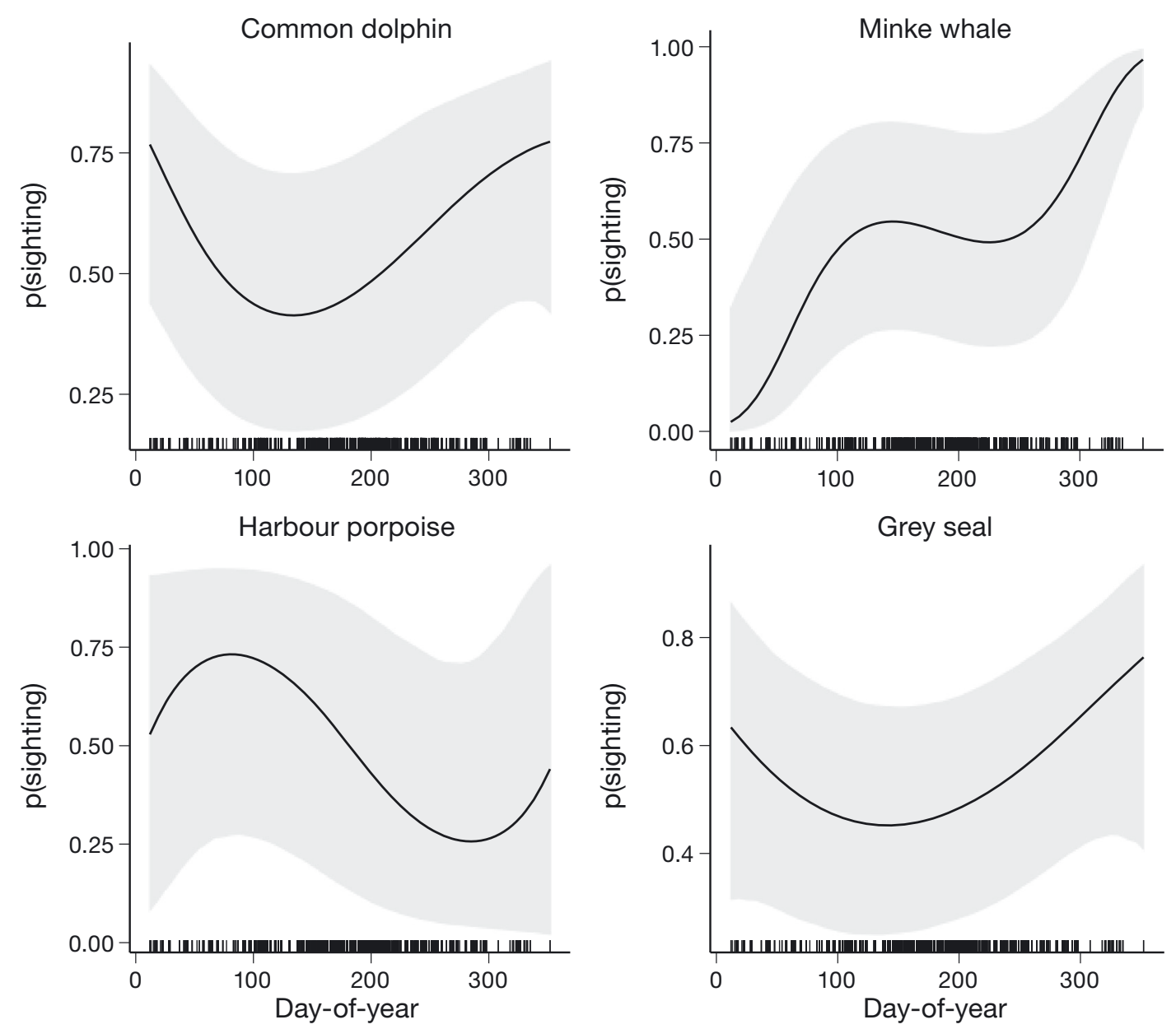

Fig. 4. Probability of sighting each of the 4 species across the day-of-year in any given year. Grey area shows the $95 \%$ CIs. Rug plots on the $x$-axes shows the distribution of the underlying data

some evidence that impulsive noise, vessel noise, dredging and electro-magnetic fields can influence some fish species' behaviour (Popper \& Hastings 2009, Gill et al. 2012, De Robertis \& Handegard 2013, Radford et al. 2014, Todd et al. 2015). Therefore, it is possible that the inter-annual variation in marine mammal occurrence in the bay could have been influenced by a combination of both direct and indirect impacts of construction-related activities within the area, as well as natural stochastic processes.

Of the construction-related activities that were involved in the gas pipeline, the majority of research investigating direct impacts on marine mammals has primarily focused on seismic surveys for exploration. These studies have documented changes in behaviour (Pirotta et al. 2014), temporary threshold shifts in hearing (Lucke et al. 2009), avoidance (Stone \& Tasker 2006), and short-term displacement (Thompson et al. 2013a). Few studies have explicitly investigated the impact of dredging, rock trenching or rock dumping on marine mammals. The noise emitted dur- ing these types of activities is most likely broadband, with most energy below $1 \mathrm{kHz}$ (Reine et al. 2014) and is therefore unlikely to cause damage to the auditory systems of marine mammals (e.g. Kastelein et al. 2002). Consequently, it is perhaps not considered an immediate cause for concern; nevertheless, there is the potential impact of masking communication calls, behavioural changes and displacement (Pirotta et al. 2013), particularly if activities directly impact on marine mammals' prey species (Todd et al. 2015).

In the present study, there was evidence to suggest that fine-scale temporal occurrence of minke whales and harbour porpoises in the bay were influenced by the presence of construction-related activity in the area, with lower occurrence rates recorded on construction-related activity days. However, given the temporal and spatial scale of the construction-related activity, and the fact that multiple activity types (e.g. dredging and acoustic surveys) did, on occasion, occur on the same day, the effect of specific activities could not be determined. With respect to minke 

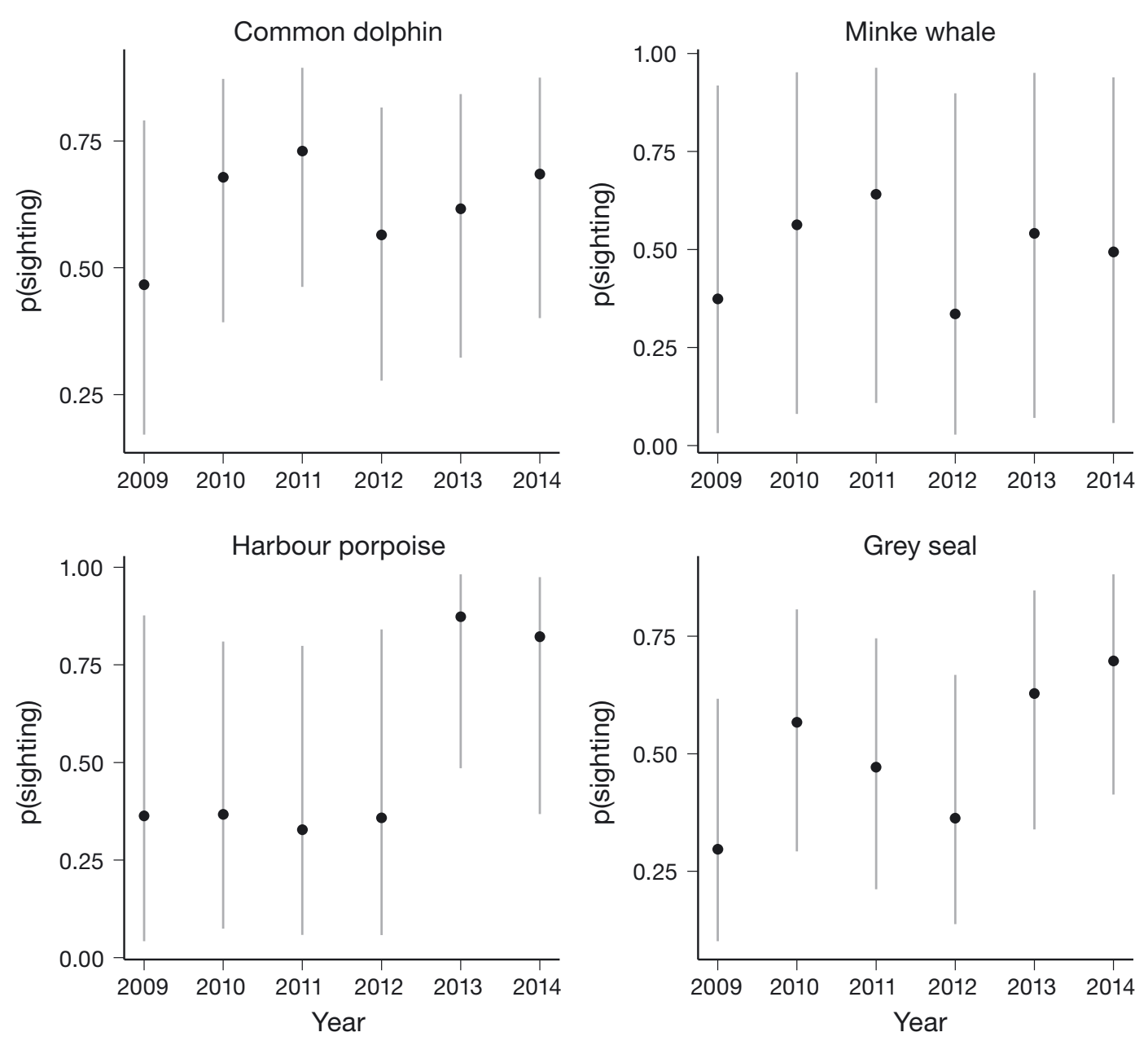

Fig. 5. Probability of sighting each of the 4 species on any given day within the year. Grey bars represent $95 \%$ CIs

whales, there is little known about their hearing range; however, it is thought that they will be more sensitive to low frequency sounds (Nowacek et al. 2007), which would suggest that seismic surveys could elicit a negative response from this species. Studies on other species of mysticete have found that individuals modify their call characteristics in response to seismic survey noise (humpback whale Megaptera novaeangliae, Risch et al. 2012; bowhead whale Balaena mysticetus, Blackwell et al. 2015) or during an increase in background anthropogenic noise (North Atlantic right whale Eubalaena glacialis, Parks et al. 2011; blue whale Balaenoptera musculus, Melcón et al. 2012). Under some scenarios, this could result in displacement from the impact zone as a direct response to reduce masking of communication calls (Stone \& Tasker 2006), for example.

To date, there have been no studies directly investigating the influence of construction-related activity on minke whales. A previous study in Broadhaven Bay did provide evidence for a negative effect of ves- sels on minke whale occurrence (Anderwald et al. 2013); however, by including previously unavailable information, the present study demonstrates that this is more likely due to construction-related activity rather than the presence of particular vessel types per se. More broadly, previous studies have identified negative impacts of whale-watching activities on this species (Christiansen et al. 2013a,b). Specifically, in the presence of boats, individuals performed shorter dives, increased their breathing rate and, during periods of interactions with whale-watching vessels, reduced their foraging activity (Christiansen et al. 2013a,b). However, these studies did not present any findings with respect to avoidance behaviour, which suggests that the driving factor(s) for the potential negative impact of construction-related activity identified in the present study are likely to be different from those caused by ecotourism vessels.

Harbour porpoises are likely to be more sensitive to anthropogenic noise compared to other odontocetes (Ketten 2000, Lucke et al. 2009). Both short-term 

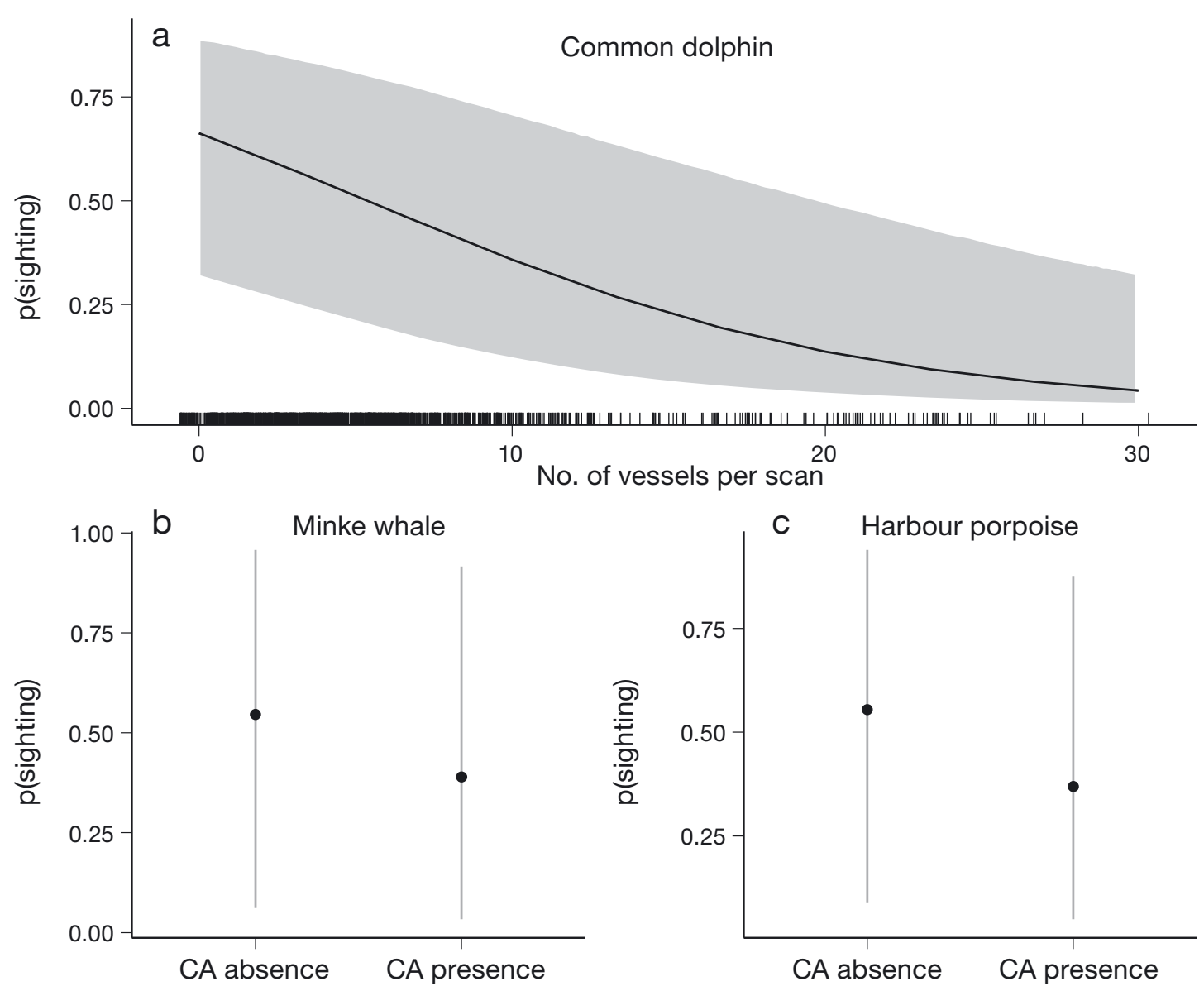

Fig. 6. (a) Influence of the number of vessels on the probability of sighting common dolphin, and influence of construction-related activity (CA) on the probability of sighting (b) minke whale and (c) harbour porpoise. Grey area in (a) and bars in (b,c) represent the $95 \%$ CIs. In (a) where present, the rug plot on the $x$-axis has a small amount of random noise added to the underlying data to better illustrate their distribution

(Thompson et al. 2013a) and long-term displacement (Teilmann \& Carstensen 2012) as well as changes in foraging behaviour (Pirotta et al. 2014) have been reported as likely consequences of construction-related activity to this species. In addition, harbour porpoises are also likely to actively avoid vessels (Hermannsen et al. 2014, Dyndo et al. 2015); however, despite the present study finding evidence of constructionrelated activity reducing porpoise occurrence in the bay, it did not find any such pattern with respect to the number of vessels within the bay. Conversely, an increase in vessel numbers did have a strong, negative influence on the occurrence of common dolphins. Other studies have found evidence of this species showing avoidance behaviour towards ecotourism vessels (Neumann \& Orams 2006) and for foraging and resting bouts to be disrupted during vessel interactions (Stockin et al. 2008, Meissner et al. 2015). However, despite construction-related activity days having a significantly higher number of vessels present, there was no evidence of a negative impact of construction-related activity on common dolphins. In contrast, Goold (1996) did find that seismic surveys impacted negatively upon common dolphin occurrence, although he suggested that avoidance behaviours may only have been over relatively short distances of $\sim 1 \mathrm{~km}$. In which case, for the present study, if the active vessel were conducting seismic surveys, then depending on its location, common dolphins could theoretically display such avoidance behaviour and still be recorded within the bay.

The present study found seasonal patterns in the occurrence of all 4 species. For common dolphins, harbour porpoises and grey seals the models showed that peaks in these species' occurrence often overlapped with times of the year when construction-related activity and vessel numbers were reduced. This may be a natural pattern in seasonal variation; indeed, Wall (2013) reported a similar seasonal pattern for common dolphins and harbour porpoises in broader Irish waters, which tentatively suggests that seasonal patterns persisted irrespective of vessel traffic or construction- 
related activity and that any impact is likely to have been short-term. The increase in grey seal occurrence rates during the autumn and winter months may be explained by the close proximity $(<10 \mathrm{~km})$ of one of Ireland's largest grey seal breeding colonies (Cronin et al. 2007) and more localised foraging behaviour during the annual breeding season between August and December (Cronin et al. 2013).

As noted previously, lower annual occurrences of the 4 species did not necessarily coincide with higher intensities of construction-related activity. This may be an indication of the variation in response to particular activities, as well as the intensity (with respect to duration of operation) and specific location of the activity in relation to the bay. As the latter was not regularly recorded in MMO reports, this limits our ability to investigate the potential for quantifying the finescale spatio-temporal impact of the diverse range of construction-related activities that occurred. Nevertheless, the observed response of the 4 species, coupled with what we know about their ecology and their spatial and temporal distribution in broader Irish waters, suggest that there were no long-term population effects as a result of construction-related activity or vessel traffic. However, a lack of empirical data often makes it difficult to quantify population consequences of disturbance, as a detailed knowledge of the spatial and temporal use of the area by the target species as well as a comprehensive understanding of the location, timing and potential impacts associated with disturbances, are required (Thompson et al. 2013b, Nabe-Nielsen et al. 2014, King et al. 2015). Even if these data are available, expert judgement is still often required to link disturbances to proxies for individual fitness, which then feed into population models (Thompson et al. 2013b, King et al. 2015).

More broadly, the present study highlights the need for better communication and coordination between developers, regulators and scientists to maximise data collection and quality, which in turn will better inform our understanding of the potential impacts and how best to mitigate against them for future developments. How this is undertaken and achieved will vary depending on the activity (e.g. pile-driving, dredging), the sensitivity of the site in relation to the species (e.g. breeding or feeding area) and the behaviour and ecology of the species of interest (Evans \& Hammond 2004, Bailey et al. 2014). One approach a monitoring programme can take for improving confidence in the conclusions of statistical models (i.e. increasing statistical power) is to increase survey effort (Taylor et al. 2007). In the case of marine mammals, survey effort is often limited by the high cost of conducting boat-based or aerial line transect surveys. Cost is less likely to be a limiting factor for shore-based surveys (Evans \& Hammond 2004). As a consequence, the present study was able to maximise survey effort by conducting year-round shore-based surveys. However, as is often the case in temperate climates like Ireland, suitable survey conditions (Beaufort sea state $<4$ and visibility $\geq 7 \mathrm{~km}$ ) are limited, especially during the autumn and winter (which can be further exacerbated by the shorter period of daylight during this time of the year). Consequently, the number of suitable survey days quite often becomes the limiting factor (notably, the same limitations would also be applicable to boat-based and aerial surveys). In scenarios where opportunities for undertaking surveys are reduced, one approach to increasing survey effort is to conduct multiple monitoring approaches simultaneously (Thompson et al. 2013a). However, this can be logistically challenging and often requires unrealistic financial investment. Furthermore, potentially influential activities not pertaining to the particular development of interest may be underway in adjacent areas, sometimes unbeknown to the researchers undertaking the monitoring. If these additional activities are not appropriately accounted for in the analysis, as was done in the present study (i.e. the seabed mapping surveys conducted by the Geological Survey of Ireland), then the ability to determine the cause of observed impacts is likely confounded (Bailey et al. 2014).

The need to quantify the potential direct and indirect anthropogenic impacts on marine mammals and other marine taxa continues to grow as applications for developments increase, particularly in the marine renewable energy sector, where technologies and devices are evolving rapidly, bringing yet another challenge to regulators (Witt et al. 2012, Benjamins et al. 2015). Consequently, regulators are under increasing pressure to ensure adequate protection of sensitive marine species in the face of multiple economic drivers for development. While there still remains a need to assess the relative impact of different construction-related activities across sensitive species for appropriate mitigation to be employed, the present study demonstrates the utility of a relatively low-cost visual monitoring programme to determine the additive effect of multiple construction-related activities at one site. Whilst this approach cannot determine the impact of individual construction-related activities in isolation, it does provide a realistic, cost-effective estimate of impacts when taken over an entire development, which may satisfy the requirements of regulators. 
Acknowledgements. The monitoring programme was funded by Shell E\&P Ireland Ltd, having been established initially by Enterprise Energy Ireland Ltd. M.J. was funded under Marine Renewable Energy Ireland (MaREI), The SFI Centre for Marine Renewable Energy Research (12/RC/ 2302). M.C. acknowledges support through a Beaufort Marine Research Award, carried out under the Sea Change Strategy and the Strategy for Science Technology and Innovation (2006-2013). Thanks go to all those that assisted in data collection and to earlier project managers Oliver Ó Cadhla, Anneli Englund and Mary Coleman. Thanks also go to Ronan O'Toole (Geological Survey Ireland) for providing the MMO reports for the INFOMAR project. We also thank Eamon Reilly and all the other landowners that allowed us access to their land in order to conduct the shore-based surveys. Finally, thank you to the 3 anonymous reviewers whose comments and suggestions improved the manuscript.

\section{LITERATURE CITED}

Anderwald P, Haberlin MD, Coleman M, Ó Cadhla O, Englund A, Visser F, Cronin M (2012) Seasonal trends and spatial differences in marine mammal occurrence in Broadhaven Bay, north-west Ireland. J Mar Biol Assoc UK 92:1757-1766

Anderwald P, Brandecker A, Coleman M, Collins C and others (2013) Displacement responses of a mysticete, an odontocete, and a phocid seal to construction-related vessel traffic. Endang Species Res 21:231-240

Bailey H, Thompson P (2010) Effect of oceanographic features on fine-scale foraging movements of bottlenose dolphins. Mar Ecol Prog Ser 418:223-233

Bailey H, Brookes KL, Thompson PM (2014) Assessing environmental impacts of offshore wind farms: lessons learned and recommendations for the future. Aquat Biosyst 10:8

Benjamins S, Dale A, Hastie G, Waggitt JJ, Lea MJ, Scott B, Wilson B (2015) Confusion reigns? A review of marine megafauna interactions with tidal-stream environments. Oceanogr Mar Biol Annu Rev 53:1-54

> Blackwell SB, Nations CS, McDonald TL, Thode AM and others (2015) Effects of airgun sounds on bowhead whale calling rates: evidence for two behavioral thresholds. PLoS One 10:e0125720

Booth CG, Embling C, Gordon J, Calderan SV, Hammond PS (2013) Habitat preferences and distribution of the harbour porpoise Phocoena phocoena west of Scotland. Mar Ecol Prog Ser 478:273-285

Boyce MS, Vernier PR, Nielsen SE, Schmiegelow FKA (2002) Evaluating resource selection functions. Ecol Modell 157:281-300

> Brandt MJ, Diederichs A, Betke K, Nehls G (2011) Responses of harbour porpoises to pile driving at the Horns Rev II offshore wind farm in the Danish North Sea. Mar Ecol Prog Ser 421:205-216

Burnham KP, Anderson DR (2002) Model selection and multimodel inference: apractical information-theoretic approach. Springer-Verlag, New York, NY

> Burnham KP, Anderson DR, Huyvaert KP (2011) AIC model selection and multimodel inference in behavioral ecology: some background, observations, and comparisons. Behav Ecol Sociobiol 65:23-35

Christiansen F, Rasmussen M, Lusseau D (2013a) Whale watching disrupts feeding activities of minke whales on a feeding ground. Mar Ecol Prog Ser 478:239-251

> Christiansen F, Rasmussen MH, Lusseau D (2013b) Inferring activity budgets in wild animals to estimate the conse- quences of disturbances. Behav Ecol 24:1415-1425

Cronin MA, Duck CD, Ó Cadhla O (2007) Aerial surveying of grey seal breeding colonies on the Blasket Islands, Co. Kerry, the Inishkea Group, Co. Mayo and the Donegal coast, Ireland. J Nat Conserv 15:73-83

> Cronin M, Pomeroy P, Jessopp M (2013) Size and seasonal influences on the foraging range of female grey seals in the northeast Atlantic. Mar Biol 160:531-539

> De Robertis A, Handegard NO (2013) Fish avoidance of research vessels and the efficacy of noise-reduced vessels: a review. ICES J Mar Sci 70:34-45

Dyndo M, Wiśniewska DM, Rojano-Doñate L, Madsen PT (2015) Harbour porpoises react to low levels of high frequency vessel noise. Sci Rep 5:11083

Embling CB, Walters AEM, Dolman SJ (2015) How much effort is enough? The power of citizen science to monitor trends in coastal cetacean species. Glob Ecol Conserv 3: 867-877

Evans PGH, Hammond PS (2004) Monitoring cetaceans in European waters. Mammal Rev 34:131-156

Fielding AH, Bell JF (1997) A review of methods for the assessment of prediction errors in conservation presence/absence models. Environ Conserv 24:38-49

Fox J, Monette G (1992) Generalized collinearity diagnostics. J Am Stat Assoc 87:178-183

Freeman EA, Moisen G (2008) PresenceAbsence: an R Package for presence-absence model analysis. J Stat Softw 23:1-31

Gill AB, Bartlett M, Thomsen F (2012) Potential interactions between diadromous fishes of UK conservation importance and the electromagnetic fields and subsea noise from marine renewable energy developments. J Fish Biol 81:664-695

> Goold JC (1996) Acoustic assessment of populations of common dolphin Delphinus Delphis in conjunction with seismic surveying. J Mar Biol Assoc UK 76:811-820

Gordon J, Berrow SD, Rogan E, Fennelly S (1999) Acoustic and visual survey of cetaceans off the Mullet Peninsula, Co. Mayo. Ir Nat J 26:251-259

Hardin J, Hilbe J (2012) Generalized estimating equations. CRC Press, Boca Raton, FL

Hegyi G, Zsolt Garamszegi L (2011) Using information theory as a substitute for stepwise regression in ecology and behavior. Behav Ecol Sociobiol 65:69-76

Hermannsen L, Beedholm K, Tougaard J, Madsen PT (2014) High frequency components of ship noise in shallow water with a discussion of implications for harbor porpoises (Phocoena phocoena). J Acoust Soc Am 136:1640-1653

> Hildebrand JA (2009) Anthropogenic and natural sources of ambient noise in the ocean. Mar Ecol Prog Ser 395:5-20

Højsgaard S, Halekoh UJY (2006) The R package geepack for generalized estimating equations. J Stat Softw 15:1-110

Kastak D, Southall BL, Schusterman RJ, Kastak CR (2005) Underwater temporary threshold shift in pinnipeds: effects of noise level and duration. J Acoust Soc Am 118: 3154-3163

Kastelein RA, Bunskoek P, Hagedoorn M, Au WWL, de Haan D (2002) Audiogram of a harbor porpoise (Phocoena phocoena) measured with narrow-band frequencymodulated signals. J Acoust Soc Am 112:334-344

> Kastelein RA, Schop J, Gransier R, Hoek L (2014) Frequency of greatest temporary hearing threshold shift in harbor porpoises (Phocoena phocoena) depends on the noise level. J Acoust Soc Am 136:1410-1418

Ketten D (2000) Cetacean ears. In: Au WWL, Popper AN, Fay RR (eds) Hearing by whales and dolphins. SpringerVerlag, New York, NY, p 43-108 
King SL, Schick RS, Donovan C, Booth C, Burgman M, Thomas L, Harwood J (2015) An interim framework for assessing population consequences of disturbance. Meth Ecol Evol 6: 1150-1158

> Lucke K, Siebert U, Lepper PA, Blanchet MA (2009) Temporary shift in masked hearing thresholds in a harbor porpoise (Phocoena phocoena) after exposure to seismic airgun stimuli. J Acoust Soc Am 125:4060-4070

- Meissner AM, Christiansen F, Martinez E, Pawley MDM, Orams MB, Stockin KA (2015) Behavioural effects of tourism on oceanic common dolphins, Delphinus sp., in New Zealand: the effects of Markov analysis variations and current tour operator compliance with regulations. PLoS One 10:e0116962

Melcón ML, Cummins AJ, Kerosky SM, Roche LK, Wiggins SM, Hildebrand JA (2012) Blue whales respond to anthropogenic noise. PLoS One 7:e32681

Mendes S, Turrell W, Lütkebohle T, Thompson P (2002) Influence of the tidal cycle and a tidal intrusion front on the spatio-temporal distribution of coastal bottlenose dolphins. Mar Ecol Prog Ser 239:221-229

Nabe-Nielsen J, Sibly RM, Tougaard J, Teilmann J, Sveegaard S (2014) Effects of noise and by-catch on a Danish harbour porpoise population. Ecol Model 272:242-251

> Neumann DR, Orams MB (2006) Impacts of ecotourism on short-beaked common dolphins (Delphinus delphis) in Mercury Bay, New Zealand. Aquat Mamm 32:1-9

Nottestad L, Krafft BA, Anthonypillai V, Bernasconi M, Langard L, Mork HL, Ferno A (2015) Recent changes in distribution and relative abundance of cetaceans in the Norwegian Sea and their relationship with potential prey. Front Ecol Evol 2:83

> Nowacek DP, Thorne LH, Johnston DW, Tyack PL (2007) Responses of cetaceans to anthropogenic noise. Mammal Rev 37:81-115

Pan W (2001) Akaike's information criterion in generalized estimating equations. Biometrics 57:120-125

Parks SE, Johnson M, Nowacek D, Tyack PL (2011) Individual right whales call louder in increased environmental noise. Biol Lett 7:33-35

> Pirotta E, Matthiopoulos J, MacKenzie M, Scott-Hayward L, Rendell L (2011) Modelling sperm whale habitat preference: a novel approach combining transect and follow data. Mar Ecol Prog Ser 436:257-272

> Pirotta E, Laesser BE, Hardaker A, Riddoch N, Marcoux M, Lusseau D (2013) Dredging displaces bottlenose dolphins from an urbanised foraging patch. Mar Pollut Bull 74: 396-402

> Pirotta E, Brookes KL, Graham IM, Thompson PM (2014) Variation in harbour porpoise activity in response to seismic survey noise. Biol Lett 10, doi:10.1098/rsbl.2013.1090

Pirotta E, Merchant N, Thompson P, Barton T, Lusseau D (2015) Quantifying the effect of boat disturbance on bottlenose dolphin foraging activity. Biol Conserv 181: 82-89

Popper AN, Hastings MC (2009) The effects of anthropogenic sources of sound on fishes. J Fish Biol 75:455-489

R Core Team (2015) R: a language and environment for statistical computing. R Foundation for Statistical Computing, Vienna. www.R-project.org/

Radford AN, Kerridge E, Simpson SD (2014) Acoustic communication in a noisy world: Can fish compete with anthropogenic noise? Behav Ecol 25:1022-1030

Reine KJ, Clarke D, Dickerson C (2014) Characterization of

Editorial responsibility: Peter Corkeron,

Woods Hole, Massachusetts, USA underwater sounds produced by hydraulic and mechanical dredging operations. J Acoust Soc Am 135: 3280-3294

> Richards SA (2008) Dealing with overdispersed count data in applied ecology. J Appl Ecol 45:218-227

Richards SA, Whittingham MJ, Stephens PA (2011) Model selection and model averaging in behavioural ecology: the utility of the IT-AIC framework. Behav Ecol Sociobiol 65:77-89

Richardson WJ, Wursig B, Greene CRJ (1990) Reactions of bowhead whales, Balaena mysticetus, to drilling and dredging noise in the Canadian Beaufort Sea. Mar Environ Res 29:135-160

Risch D, Corkeron PJ, Ellison WT, van Parijs SM (2012) Changes in humpback whale song occurrence in response to an acoustic source $200 \mathrm{~km}$ away. PLoS One 7:e29741

Sing T, Sander O, Beerenwinkel N, Lengauer T (2005) ROCR: visualizing classifier performance in R. Bioinformatics 21:3940-3941

Stockin KA, Pierce GJ, Binedell V, Wiseman N, Orams MB (2008) Factors affecting the occurrence and demographics of common dolphins (Delphinus sp.) in the Hauraki Gulf, New Zealand. Aquat Mamm 34:200-211

Stone CJ, Tasker ML (2006) The effects of seismic activity on marine mammals in UK waters, 1998-2000. J Cetacean Res Manag 8:255-263

> Taylor BL, Martinez M, Gerrodette T, Barlow J, Hrovat YN (2007) Lessons from monitoring trends in abundance of marine mammals. Mar Mamm Sci 23:157-175

Teilmann J, Carstensen J (2012) Negative long term effects on harbour porpoises from a large scale offshore wind farm in the Baltic-evidence of slow recovery. Environ Res Lett 7:045101

> Thompson PM, Brookes KL, Graham IM, Barton TR, Needham K, Bradbury G, Merchant ND (2013a) Short-term disturbance by a commercial two-dimensional seismic survey does not lead to long-term displacement of harbour porpoises. Proc R Soc B 280:20132001

Thompson PM, Hastie GD, Nedwell J, Barham R and others (2013b) Framework for assessing impacts of pile-driving noise from offshore wind farm construction on a harbour seal population. Environ Impact Assess Rev 43:73-85

Todd VLG, Todd IB, Gardiner JC, Morrin ECN, MacPherson NA, DiMarzio NA, Thomsen F (2015) A review of impacts of marine dredging activities on marine mammals. ICES J Mar Sci 72(2):328-340

Wall D (2013) Marine mammals and megafauna in Irish waters - behaviour, distribution and habitat use. Monitoring spatial and temporal habitat use and abundance of cetaceans. Marine Research Sub-Programme (NDP 2007-'13), PBA/ ME/07/005(02). http://hdl.handle.net/10793/869

- Whittingham MJ, Stephens PA, Bradbury RB, Freckleton RP (2006) Why do we still use stepwise modelling in ecology and behaviour? J Anim Ecol 75:1182-1189

Witt MJ, Sheehan EV, Bearhop S, Broderick AC and others (2012) Assessing wave energy effects on biodiversity: the Wave Hub experience. Philos Trans R Soc A Math Phys Eng Sci 370:502-529

Zuur AF, Ieno EN, Walker NJ, Saveliev AA, Smith GM (2009) Mixed effects models and extensions in ecology with R. Springer, New York, NY

Zweig MH, Campbell G (1993) Receiver-operating characteristic (ROC) plots: a fundamental evaluation tool in clinical medicine. Clin Chem 39:561-577

Submitted: December 22, 2015; Accepted: March 4, 2016

Proofs received from author(s): April 22, 2016 